\title{
A study on the Health Warning of Provincial Capital Cities in China based on the Normalized Model
}

\author{
Guoquan Qian ${ }^{1,2^{*}}$, Jinxiang Wang ${ }^{1,2}$, Xiaoying $\mathrm{Nie}^{1}$, Mingtao $\mathrm{Li}^{1}$ and Tianpeng $\mathrm{Gao}^{2,3^{*}}$ \\ ${ }^{1}$ College of Geography and Environmental engineering, Lanzhou City University, Lanzhou 730070, China \\ ${ }^{2}$ Engineering Research Center of Mining Pollution Treatment and Ecological Restoration of Gansu Province, Lanzhou City University, \\ Lanzhou 730070, China \\ ${ }^{3}$ School of biology and environmental engineering, Xi'an University, Xi' an 710065, China.
}

\begin{abstract}
Along with the rapid advance of urbanization, urban disease appear. For detection city disease earlier, the ecological city is put in this article. The ecological city is regarded as the human body to plan, construct and manage city with the thought of "law in the human body". The city's population, land, water, air, transportation, culture, are considered as the body's nerves, muscles, blood, breath, limbs and the vigor, respectively. And a quantitative standard is determined for each object of study. If the quantitative value is abnormally large or small, it indicates that the city is unhealthy, the early warning system for city will put forward, the causes will lookup and the treatment will give.
\end{abstract}

\section{Introduction}

China's urbanization is advancing rapidly, with the urbanization rate of permanent residents rising from 17.9 percent in 1978 to 60.6 percent in 2019. In 2019, there will be 684 cities, 21,013 towns, and 60,300 square kilometers of built-up urban areas. With the rapid growth of the number of cities, "urban diseases" also appear, such as population expansion, housing shortage, employment difficulties, traffic congestion, environmental degradation and frequent public security incidents etc. It not only hinders the healthy and orderly development of the city, but also affects the quality of life of residents ${ }^{[1]}$. Under this background, it is proposed to establish urban early warning system and scientifically govern the city.

\section{The theoretical basis of the establishment of urban early warning system}

In 1933, the Athens Charter put forward the "organic city" for the first time, which believed that the various functions of a city should be laid out reasonably and run smoothly. In 1977, the Charter of Machu Picchu proposed that as a living organism, the inner order of a city is formed through the self-organizing behavior caused by the complex interaction of various components in the system, and maintains the balance of "life" in the overall association. In 1943, Finnish scholar Eliel Saarinen gave a systematic exposition of the theory of urban organic evacuation in his book The City, Its Growth, Decline and Future. He thought tends to decline of city today, need to have a on the basis of the principle of reasonable urban planning, the revolutionary changes in the structure of the city has a good, for the healthy development of heavy industry layout and light industry should be evacuated from the city center, only the enterprise administrative department and urban layout in in the center of the city, Large areas of land left vacant by industrial relocation in central urban areas should be used to increase green space and residential land for technicians, administrative personnel and business people who must work in central urban areas so that they can enjoy family life close to them. He believed that such a structure should not only accord with the nature of human habitation, but also facilitate people to live a common social life and feel the pulse of the city, while not divorced from the nature ${ }^{[2]}$.

In 2019, Professor Yang Zhi ${ }^{[3]}$, dean of the School of Marxism at Harbin Institute of Technology, took charge of the major research project of philosophy and social sciences of the Ministry of Education, "Theoretical Research on Socialist Urban Organism with Chinese Characteristics". He also proposed the idea that cities are living organisms.

Based on the above understanding of the city as a living entity ${ }^{[4]}$, we believe that the urban construction with Chinese characteristics can be planned, constructed and managed with the idea of "law in human body". The core of "Law on Human Body" is to treat the city as an organism like human being, in which the population is like human's nerves to the city. Land to the city is like human muscle; Water to a city is like human blood, and air is like human breath to a city. Traffic to the city, like human limbs; Culture is as vital to a city as it is to a person. Planning, construction and management of cities to the most basic

*Corresponding author: 599037529@qq.com; zkgtp@163.com; ORCID: 0000-0001-6821-3836 
elements of the population, land, water, air, transportation, culture, as the research object, for each basic elements to determine a quantitative standard, if these basic elements of quantitative values unusually large or small, lesions appears in the city, city to put forward the corresponding early warning, To find out the causes of urban diseases and give the corresponding treatment plan ${ }^{[5,6]}$.

\section{Empirical research}

\subsection{The determination of early warning index of urban disease}

Table1. Warning Value of City Disease

\begin{tabular}{|c|c|c|c|}
\hline $\begin{array}{c}\text { Physical } \\
\text { objects }\end{array}$ & Physical indicators & Prewarning value & $\begin{array}{c}\text { Physical } \\
\text { examination result } \\
\end{array}$ \\
\hline \multirow[t]{2}{*}{ population } & 1. Population density & $\begin{array}{l}\text { Population greater than } 10,000 \\
\text { per square kilometer or less } \\
\text { than } 5,000 \text { per square kilometer }\end{array}$ & unhealthy \\
\hline & $\begin{array}{l}\text { 2. The difference between the } \\
\text { urbanization rate of household } \\
\text { registration and the urbanization rate } \\
\text { of permanent resident population }\end{array}$ & More than $10 \%$ & unhealthy \\
\hline \multirow[t]{2}{*}{ land } & 3. Green coverage in built-up areas & Less than $41 \%$ & unhealthy \\
\hline & $\begin{array}{l}\text { 4. Land use and development } \\
\text { intensity }\end{array}$ & $\begin{array}{l}\text { The investment per mu of land } \\
\text { should not be less than } 1 \\
\text { million yuan }\end{array}$ & unhealthy \\
\hline \multirow[t]{2}{*}{ water } & 5. Sewage treatment rate & Less than $97 \%$ & unhealthy \\
\hline & $\begin{array}{l}\text { 6. Per Capita Daily Domestic Water } \\
\text { Consumption }\end{array}$ & $\begin{array}{l}\text { More than } 530 \text { cubic meters or } \\
\text { less than } 330 \text { cubic meters }\end{array}$ & unhealthy \\
\hline \multirow[t]{2}{*}{ air } & 7. Good air quality days & less than 310 days & unhealthy \\
\hline & $\begin{array}{l}\text { 8. Inhalable particulate matter in the } \\
\text { air, PM10 }\end{array}$ & $\begin{array}{c}\text { More than } 150 \text { milligrams per } \\
\text { cubic meter }\end{array}$ & unhealthy \\
\hline \multirow[t]{2}{*}{ traffic } & $\begin{array}{l}\text { 9. The time it takes a motor vehicle to } \\
\text { travel } 10 \text { kilometers }\end{array}$ & More than 30 minutes & unhealthy \\
\hline & $\begin{array}{l}\text { 10. The quotient of motor vehicle } \\
\text { ownership and per capita road area }\end{array}$ & Less than 4 & unhealthy \\
\hline \multirow[t]{2}{*}{ cultural } & $\begin{array}{l}\text { 11. College degree or above per } \\
100,000 \text { people }\end{array}$ & Less than 10,000 & unhealthy \\
\hline & $\begin{array}{l}\text { 12. Percentage of cultural industries } \\
\text { in GDP }\end{array}$ & Less than $5 \%$ & unhealthy \\
\hline
\end{tabular}

\subsection{Comprehensive study by model normalization method}

Six indicators, including population density, green coverage rate of urban construction, sewage treatment rate, days with good air quality, public satisfaction rate of urban traffic, and the proportion of the tertiary industry, were used as the early warning value index of urban diseases. The comprehensive index of 31 provincial capitals was calculated by the comprehensive index method ${ }^{[7]}$. The main calculation process was divided into the following three steps:

Step 1: Standardize the data

Since the units of the six indicators are different, in order to make comprehensive analysis among the indicators by mathematical methods and standardize or non-dimensional processing of the data, the following methods are adopted:

Representation of positive indicators:

$$
X=X_{i} / X_{r e f}
$$

Representation of a negative index:

$$
X=X_{r e f} / X_{i}
$$

Representation of a semi-positive index:

$X=\left\{\begin{array}{l}X_{i} / X_{r e f}, \text { When } X_{\mathrm{i}} \text { is less than } X_{r e f} \\ X_{r e f} / X_{i}, \text { When } X_{\mathrm{i}} \text { is less than } X_{r e f}\end{array}\right.$ 
Where $X$ represents the standardized assignment of data indicators, $X_{i}$ represents the original data collected by data indicators, and $X_{r e f}$ is the reference standard value of data indicators. In order to facilitate calculation, the reference standard value $X_{\text {ref }}$ can be selected in the following three situations:

$$
\begin{aligned}
& X_{r e f}=\lambda \max _{\mathrm{i}} X_{i} \\
& X_{\text {ref }}=\lambda \operatorname{mix}_{\mathrm{i}} X_{i} \\
& X_{\text {ref }}=\lambda \underset{\mathrm{i}}{\operatorname{ave}} X_{i}
\end{aligned}
$$

Where $\lambda=1$.

Step 2: index weight determination -- entropy value method

Since the aspects reflected by the early warning value of various indicators for urban diseases are not completely average, it is necessary to classify the indicators and introduce the concept of weight to make the evaluation system more objective and reasonable. Entropy method is to determine the weight of each index according to the amount of information provided by the observation value of each index. The main basis of this method is to use the difference degree of the observed values to determine the weight of the index (the greater the difference of the observed values, the greater the weight, and otherwise, the smaller the weight). Calculation steps:

Index weight is to determine the importance of each index to the whole index evaluation system. Entropy value method is to determine the weight of each index according to the variation degree of measured value, which belongs to objective weighting method. Entropy value method is used to calculate the weight of each index in this report, which provides a basis for comprehensive evaluation of multiple indexes. The specific calculation process is divided into the following three steps:
1) Calculate the entropy value of each index:

$$
U_{\mathrm{j}}=-\sum_{\mathrm{i}=1}^{\mathrm{m}} X_{i \mathrm{j}} \ln X_{i \mathrm{j}}
$$

Where $m$ is the sample number;

2) Entropy reverse:

$$
S_{\mathrm{j}}=\frac{\max U_{\mathrm{j}}}{U_{\mathrm{j}}}
$$

3) Determine the weight:

$$
W_{\mathrm{j}}=\frac{S_{\mathrm{j}}}{\sum_{\mathrm{j}=1}^{\mathrm{n}} S_{\mathrm{j}}}, \quad(\mathrm{j}=1,2, \ldots \mathrm{n})
$$

Step 3: Calculation of composite index

The comprehensive index of the early warning value of the urban disease in the whole region can be calculated by integrating all indicators. The calculation formula is as follows: $E Q(t)=\sum_{\mathrm{i}=1}^{\mathrm{n}} W_{i}(\mathrm{t}) \times X_{i}(\mathrm{t}), \quad(\mathrm{i}=1,2, \ldots \mathrm{n})$

Where, Wi is the weight of evaluation index I; Xi represents the standardized value of the evaluation index; $\mathrm{N}$ is the total number of indicators.

The weight calculation results of the six indicators are shown in Table 2. It can be seen that the sewage treatment rate with the largest weight reaches $38.30 \%$, indicating that sewage treatment is the most important factor causing urban diseases.

Using the model to calculate the comprehensive index of the urban disease early warning index of 31 cities(Table 3 ), it can be seen that the three cities with the highest comprehensive index are Beijing, Guangzhou and Haikou respectively, and the indexes are 4.8919, 4.7172 and

\begin{tabular}{|c|c|c|c|c|}
\hline Rank & Level 3 indicators & $\begin{array}{c}\text { Indicators of } \\
\text { entropy } / \mathbf{U} \mathbf{j}\end{array}$ & $\begin{array}{l}\text { The entropy is } \\
\text { reversed/Sj }\end{array}$ & $\begin{array}{l}\text { Index } \\
\text { weight }\end{array}$ \\
\hline 1 & Sewage treatment rate $/ \%$ & 2.0503 & 4.7358 & 0.3830 \\
\hline 2 & Green coverage rate in built-up areas $/ \%$ & 4.1959 & 2.3142 & 0.1871 \\
\hline 3 & Good air quality days/Day & 5.5564 & 1.7475 & 0.1413 \\
\hline 4 & The proportion of the tertiary industry in GDP & 6.3544 & 1.5281 & 0.1236 \\
\hline 5 & Density of population & 9.3278 & 1.0410 & 0.0842 \\
\hline 6 & $\begin{array}{c}\text { Number of civil vehicles/ length of urban road }(10,000 \\
\text { vehicles } / \mathrm{km})\end{array}$ & 9.7100 & 1.0000 & 0.0809 \\
\hline
\end{tabular}
4.6861 respectively, indicating that the construction of these cities is relatively healthy. The three cities with the lowest composite index were Zhengzhou, Shijiazhuang and $\mathrm{Xi}$ 'an.

Table2. The index weight of early warning value index of urban disease 
Table3. The comprehensive index of early warning value index of urban disease

\begin{tabular}{|c|c|c|c|c|c|c|c|c|}
\hline Rank & City & $\begin{array}{c}\text { Comprehensive } \\
\text { index }\end{array}$ & Rank & City & $\begin{array}{c}\text { Comprehensive } \\
\text { index }\end{array}$ & Rank & City & $\begin{array}{c}\text { Comprehensive } \\
\text { index }\end{array}$ \\
\hline 1 & Beijing & 4.8919 & 12 & Fuzhou & 4.1044 & 23 & Wuhan & 3.7729 \\
\hline 2 & Guangzhou & 4.7172 & 13 & Jinan & 4.0097 & 24 & Taiyuan & 3.7320 \\
\hline 3 & Haikou & 4.6861 & 14 & Xining & 4.0072 & 25 & Changsha & 3.7118 \\
\hline 4 & Nanjing & 4.6581 & 15 & Shanghai & 3.9644 & 26 & Chengdu & 3.6902 \\
\hline 5 & $\begin{array}{c}\text { Urumqi } \\
\text { Municipality }\end{array}$ & 4.5986 & 16 & Shenyang & 3.9435 & 27 & Hohhot City & 3.6879 \\
\hline 6 & Lhasa City & 4.5664 & 17 & Hangzhou & 3.9241 & 28 & Nanchang & 3.6727 \\
\hline 7 & Changchun & 4.4639 & 18 & Tianjin & 3.9203 & 29 & Xi'an & 3.5752 \\
\hline 8 & Chongqing & 4.2817 & 19 & Yinchuan & 3.9157 & 30 & Shijiazhuang & 3.3976 \\
\hline 9 & Kunming & 4.2179 & 20 & Harbin & 3.8338 & 31 & Zhengzhou & 3.2277 \\
\hline 10 & Nanning & 4.1453 & 21 & Hefei & 3.8236 & & & \\
\hline 11 & Guiyang & 4.1150 & 22 & Lanzhou & 3.7842 & & & \\
\hline
\end{tabular}

\section{Conclusion}

The Tao Te Ching says, "People act according to the earth, the earth acts according to the heaven, the heaven acts according to the Tao, and the Tao acts according to the nature." The development of a city should also follow this rule. A city is also a complex organism, and a regular physical examination should be carried out on the main indicators, such as population, land, water, air, traffic and culture. According to the changes in these indicators, prevention should be carried out and the appropriate medicine should be applied, so that a city can develop healthfully.

\section{Acknowledgments}

The research was funded by the National Natural Science Foundation of China (31860176), Key Research and Development Program of Gansu Province (20YF3FA037), Key Research and Development Program of Shaanxi Province (2020ZDLSF06-06). We are grateful to all anonymous reviewers whose comments improved the quality of the manuscript.

\section{References:}

1. M C Li, Journal of Shanghai University of International Business and Economics, 26, 9099(2019)

2. F T Liang, Y N Cai, Huazhong Architecture, 39, 2529(2021)

3. Z Yang, China Renmin University Press (2014)

4. Q Zhao, L P Zhang, Z T Chen, Marine Environmental Science, 28, 92-95+112(2009)

5. M F Wu, Hohai University, 2006.
6. L P Zhang, W Q Chen, H S Hong, Journal of Xiamen University (Natural Science), 221-224(2004)

7. L Zhang, North China University of Water Resources and Electric Power (2013) 